\title{
Environmental Reporting by the Fortune 50 Firms
}

PAIGE DAVIS-WALLING

GE Plastics

1 Lexan Lane, Building 45

Mt. Vernon, Indiana 47620, USA

\section{STUART A. BATTERMAN*}

Environmental and Industrial Health

University of Michigan

109 Observatory Drive

Ann Arbor, Michigan 48109-2029, USA

ABSTRACT / The extent and use of industry-reported environmental data are increasing, warranting an in-depth analysis of this information. This paper reviews the environmental reporting guidelines issued by several business and nonprofit organizations and evaluates the environmental reports published by the Fortune 50 companies, half of which publish reports. After describing the history of environmental reporting and the content of the guidelines, a comparative evaluation is made to indicate the types of companies producing reports, the topics reported, the intended audiences, the scope and depth of the material reported, and the effectiveness of the reports as communication devices. These reports are mechanisms to enhance a firm's image, public relations, and marketing and are aimed largely at concerned individuals, affected communities, and investors. Significant differences in the content and the depth of reports are seen as firms report on topics that are perceived by the public as high risks. The most complete reports are published by industries with poor or controversial public images, e.g., the chemical and timber industries. Still, no report provided information that was sufficient for comprehensive or comparative analyses of environmental performance. Recommendations are provided to increase the quality and effectiveness of environmental reporting.
An increasing number of firms are writing and distributing reports that describe environmental concerns and activities. The objectives of these reports, rarely stated explicitly, may include reassuring host communities that local facilities are not hazardous, persuading employees regarding the firm's environmental intentions, showing investors that the company will not be sunk by environmental risks and liabilities, and convincing environmentalists that the firm is making environmental progress (Naimon 1993). Additional reasons may include external pressures by company stakeholders demanding information on environmental performance and internal pressure by managers needing information to better run the business (Sandborg 1993). Environmental reports also may present specific information designed to address and perhaps allay concerns of a specific audience (Forrest and Axelrod 1995). These reports can serve multiple purposes and thus vary in the information provided, presentation, intended audience, and overall quality.

While a few studies have analyzed aspects of environmental reporting, no study has provided a comprehensive examination of their content and the motivations of firms that issue them. Additionally, the principles and

KEY WORDS: Communication; Environmental management; Performance reporting; Reporting; Stakeholder

*Author to whom correspondence should be addressed (e-mail: stuartb@umich.edu). guidelines for environmental reporting that have been recently issued by several organizations have not been thoroughly reviewed. As the importance and use of voluntary disclosures appear to be increasing, a critical examination of environmental reporting is warranted. This paper examines the history and development of environmental reports, focusing on the reports issued by the 50 largest US corporations, and the guidelines developed by several organizations.

\section{History}

Following the mandatory reporting of quantitative emission data for the toxic release inventory (TRI) system that started in the late 1980s, firms in the U nited States and Europe began to publish and distribute reports detailing their environmental programs. These voluntary reports allowed firms to place emission data in the context of the firm's overall environmental management efforts and to include more descriptive information regarding their environmental performance than permitted by the TRI format. Additional impetus for reporting environmental information was provided by the US Securities and Exchange Commission (SEC), which issued a bulletin in 1993 that required publicly held firms to disclose "environmental exposures" exceeding $\$ 100,000$ in their annual reports (Forrest and Axelrod 1995). The SEC also intensified its scrutiny of environmental disclosures, particularly for industries affected by environmental risks (Knapp and 
Table 1. Rank and name of Fortune 50 companies $^{a}$

\begin{tabular}{|c|c|c|c|}
\hline Rank and firm name & Report published & Rank and firm name & Report published \\
\hline 1. General Motors & $*$ & 26. Xerox & (1) \\
\hline 2. Ford Motor & & 27. Sara Lee & $*$ \\
\hline 3. Exxon & $*$ & 28. McDonnell Douglas & \\
\hline 4. International Business Machines & $*$ & 29. Digital Equipment & (3) \\
\hline 5. General Electric & $*$ & 30. Johnson \& Johnson & $*$ \\
\hline 6. Mobil & $*$ & 31. Minnesota Mining $\& M$ an. & $*$ \\
\hline 7. Philip Morris & $*$ & 32. Coca-Cola & \\
\hline 8. Chrysler & (3) & 33. International Paper & $*$ \\
\hline 9. Texaco & $*$ & 34. Tenneco & \\
\hline 10. E.I.DuPont de Nemours & $*$ & 35. Lockheed & \\
\hline 11. Chevron & & 36. Georgia-Pacific & $*$ \\
\hline 12. Proctor and Gamble & $*$ & 37. Phillips Petroleum & $*$ \\
\hline 13. Amoco & $*$ & 38. Allied-Signal & \\
\hline 14. Boeing & $(2)$ & 39. IBP & \\
\hline 15. PepsiCo & & 40. Goodyear Tire & \\
\hline 16. ConAgra & & 41. Caterpillar & \\
\hline 17. Shell Oil & & 42. Westinghouse Electric & $*$ \\
\hline 18. United Technologies & $*$ & 43. Anheuser-Busch & \\
\hline 19. H ewl ett-Packard & & 44. Bristol-M yers Squibb & $*$ \\
\hline 20. Eastman Kodak & $*$ & 45. Rockwell International & $*$ \\
\hline 21. Dow Chemical & $*$ & 46. Merck & $*$ \\
\hline 22. Atlantic Richfield & & 47. Coastal & \\
\hline 23. Motorola & (3) & 48. Archer Daniels Midland & \\
\hline 24. USX & & 49. Ashland Oil & \\
\hline 25. RJR Nabisco Holdings & & 50. Weyerhaeuser & $*$ \\
\hline
\end{tabular}

aAsterisk indicates an environmental report was published in 1993-1994. (1) Xerox issued a report in mid-1995. (2) Boeing is expected to issue a report in 1995. (3) Chrysler, Motorola and Digital Equipment are considering reports.

others 1994). Environmental reports allowed firms to supplement financial information with management and regulatory information that was addressed to stockholders, the financial community, and others.

Chemical and petroleum companies were among the first to publish environmental reports (Forrest and Axelrod 1995), with one of the first being issued by Polaroid in 1989 ( Naimon 1993). The number of firms publishing reports has greatly increased, and a recent survey found 105 firms worldwide that published reports (KPMG 1993). This survey indicated that the largest number of reports was published by the oil and gas industry, followed by the chemical industry. Many other industries have begun to publish environmental reports.

Business and nonprofit organizations have recognized the growing need and importance of environmental reporting, and several have issued guidelines that encourage or prescribe communication of environmental information. Many firms follow these guidelines.

\section{Data Sources and Analysis}

Environmental reporting guidelines were obtained from the principal organizations in this area and examined with respect to the environmental reports issued by the Fortune 50 firms. The 1994 Fortune 50 companies, the 50 largest US firms based on total 1993 US sales volume (Dun and Bradstreet 1994), are a cross-section of the larger industries. Each of these firms (listed in Table 1) was contacted and a copy of any available environmental report was requested. Every effort was made to either receive a report or confirm that no report was published, e.g., frequently several telephone calls were necessar y to confirm the status of an environmental report. A few companies were contacted by mail or by reply card from a previous report. Most often, communications and environmental departments had knowledge of the availability of reports. In-depth discussions and interviews were held with report writers, if accessible.

After collecting available reports, topics mentioned in at least four reports were identified. The 29 topics identified (Table 2) were classified into six broad categories, i.e., corporate policies and investments, community involvement, employee involvement, regulatory concerns, pollution prevention, and miscellaneous. Several reports contained additional sections discussing health and safety topics, e.g., the number of reportable OSHA violations. Often, these reports were entitled "environmental, health and safety report," rather than "environmental report." Since environmen- 
Table 2. Categories, topics, and scoring system used to evaluate environmental reports

Category Rating system

Corporate policies and investments

1. Corporate commitment

2. Environmental auditing

2. Environmental auditing

3. Environmental management structure

4. Environmental policy

5. Industry involvement

6. Research and development

7. Support of environmental organizations

8. Total environmental expenditures

\section{Regulatory}

1. Air emissions

2. Environmental compliance

3. Reduction in ODC use

4. Remediation

5. Superfund status

6. Underground storage tanks (UST)

7. Wastewater treatment

\section{Pollution prevention}

1. Energy conservation

2. Life-cycle analyses

3. Packaging reductions

4. Recycling

5. Reuse of recycled materials

6 . Waste reduction efforts

\section{Employee involvement}

1. Employee environmental education programs

2. Employee recognition/ awards

Community involvement

1. Community involvement

2. Community panels/ information centers

3. Emergency response teams

\section{Miscellaneous}

1. Awards

2. Response card

3. Wildlife Management/ ecology
$1=$ signed statement of environmental commitment from high-level management but no numerical goals

2 = signed statement with numerical goals

$1=$ general information on an environmental auditing programs

$2=$ signed statement with numerical goals

$1=$ general information on an environemental auditing programs

2 = specific information/data on environ. auditing programs

$1=$ breakdown of environmental management structure

$1=$ written environmental policy in report

$1=$ specific information on company's environmental association

$1=$ general statements about environmental research

2 = specific information on environmental research

$1=$ specific information on financial support of environmental organizations

$1=$ support numbers present in report

$1=$ Toxic release inventory $(\mathrm{TRI})$ data presented

$2=$ TRI data plus other air emissions data (ODC, carcinogens)

$1=$ specific information on environmental violations/ fines

$1=$ general statements about use of ozone-depleting chemicals

$2=$ specific data on the use of ODCs

$1=$ information provided on remediation efforts

$1=$ information on Superfund liabilities

1 = information about UST removal program present

$1=$ general statements about wastewater treatment

2 = specific numbers on wastewater treatment efforts

$1=$ general information on energy conser vation efforts

$2=$ specific information on energy reduction efforts

$1=$ specific information as to how life cycle analyses are used to evaluate products

$1=$ information on packaging reduction efforts

$1=$ general information on recycling efforts

2 = specific information/ data on recycling efforts

$1=$ specific information on company's use of recycled materials in manufacturing

$1=$ general information on waste reduction efforts

2 = specific information/ data on waste reduction efforts

$1=$ specific information on programs to educate employees on environmental issues

$1=$ information on employee recognition programs for environmental efforts

$1=$ information provided on firm involvement in community environ. issues

$1=$ specific information on community panels or info. centers

$1=$ information on emergency response teams

$1=$ specific information on environmental awards received

$1=$ response card provided for feedback on report

$1=$ specific information on wildlife management or ecology programs tal reports are not written to convey health and safety information and thus usually omit this information, health and safety topics were excluded from this analysis.

Each topic was scored with a 0,1 , or 2, based on the detail provided in the report. A score of 0 indicates that a topic was not mentioned. Requirements for higher scores are shown in Table 2. Mentioning an extensive recycling program, for example, would warrant a score of 1 in this topic. Specific information was required to 
receive a score of 2, e.g., data on recycling tonnage or progress based on previous years. Some categories, e.g., presence of emergency response teams, were scored with a 0 or 1 . Topic scores were summed to provide category scores and a total score for each firm.

A cross-sectional analysis was performed by classifying the 50 firms using their two digit standard industrial classification (SIC) code. In all, 11 SIC codes were used. Most firms had several SIC codes, and some had over ten. A company was placed into a SIC category only if it was among the top 50 companies within that SIC code (based on sales volume) (Dun and Bradstreet 1994). Firms were placed in one to four SIC codes (Table 3). Average scores in each SIC code were compared to the global average using a two-tailed t test and a significance level of 0.05 .

\section{Results}

\section{Reporting Guidelines}

The first of five reporting guidelines discussed was developed under the sponsorship of the International Chamber of Commerce (ICC), a worldwide business organization. In 1990, a task force of business representatives wrote the Business Charter for Sustainable Development: Principles for the Environ ment. The charter includes compliance and reporting. While communication is encouraged, its form and content is not specified other than that the firm should "periodically provide appropriate information to the Board of Directors, shareholders, employees, the authorities and the public" (ICC 1991).

The Public Environmental Reporting Initiative's (PERI) Guidelines for Environmental Reporting were written by a group of environmental, health and safety professionals for "developing a comprehensive and credible framework for environmental reporting, encouraging environmental reporting itself, providing a balanced perspective on environmental policies, practices and performance, and better meeting public expectations" (PERI 1993). The guidelines specify that environmental reports should contain information on the firm's organizational profile, environmental policy, environmental management, environmental releases, resource conservation, environmental risk management, environmental compliance, product stewardship, employee recognition, and stakeholder involvement. While very specific, the guidelines emphasize the presentation of often existing or relatively easy-to-collect data, e.g., emission data (from TRI) and environmental compliance (number of environmental fines).

The European Chemical Industry Council (CEFIC), a voluntary council of European chemical manufactur- ers, published draft Guidelines on Environ mental Reporting for the European Chemical Industry that presented an outline for environmental reporting for the chemical industry. CEFIC (1993) stated that "increasingly companies are facing the need to publish information on their environmental performance. Releasing such data is essential to meet the public's demand for information and to match emerging regulatory requirements." The outline includes an environmental policy, a chairman's statement, and descriptions of new technologies, product stewardship, environmental protection spending, emission data, environmental management systems, and contact personnel. While the outline is fairly specific, information should be adapted to "site specifications and local expectations" (CEFIC 1993).

The Coalition for Environmentally Responsible Economies (CERES) is a nonprofit organization composed of investors, environmental groups, labor organizations, and public interest groups that collectively represent over 10 million people and $\$ 150$ billion in invested assets (Cahill and Kane 1994). The CERES principles require signatories to prepare an extensive annual report that includes information on biosphere protection, natural resources, reduction and disposal of wastes, energy conservaiton, risk reduction efforts, safe products and services, environmental restoration, and management commitment (CERES 1992). The information requested by CERES is ver y specific. To meet these requirements, the report of one company (GeorgiaPacific) consisted of 25 pages of text.

The emphasis and format of the reporting guidelines reflect, in part, the motivations of their authors. For example, the CERES principles, which go into the most depth, were written by nonbusiness interests. In contrast, ICC, PERI, and CEFIC guidelines are consensus documents written by business-oriented consortia. As the CEFIC guidelines make clear, public demand is the overriding factor in determining what information to include. This appears to apply to all of the guidelines and principles. Some topics of interest and importance to the public and prominently featured in the environmental reports may be largely symbolic, primarily for public relations and image-building. For example, reports by International Paper and Phillips display photographs and stories about Earth Day tree-planting activities.

Many other organizations have interests in environmental reporting and may become involved in guidance. For example, the chemical industry's Responsible Care Program mandates a dialog with the public, although environmental reports are not specifically required. The Responsible Care Program has stimulated environmental reporting more than any other 
Table 3. Scores of Fortune 50 firms publishing environmental reports

\begin{tabular}{|c|c|c|c|c|c|c|c|c|c|c|c|c|c|c|c|c|c|c|c|c|c|c|c|c|c|}
\hline \multirow[b]{2}{*}{$\begin{array}{l}\text { Topic area } \\
\text { and topic }\end{array}$} & \multicolumn{5}{|c|}{ Oil, gas and petrol } & \multicolumn{3}{|c|}{ Food } & \multicolumn{5}{|c|}{ Wood and paper } & \multicolumn{5}{|c|}{ Chemicals } & \multicolumn{7}{|c|}{ Others } \\
\hline & $\begin{array}{l}\stackrel{8}{ } \\
\stackrel{8}{<}\end{array}$ & $\begin{array}{l}\text { 亏े } \\
\text { x }\end{array}$ & $\begin{array}{l}\overline{\overline{0}} \\
\overline{0}\end{array}$ & 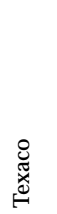 & 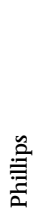 & 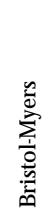 & 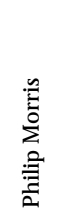 & 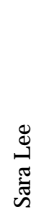 & 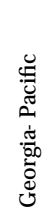 & 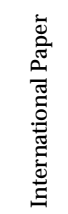 & $\begin{array}{l}\bar{y} \\
\frac{8}{0} \\
\frac{5}{5} \\
\sum_{0}^{4} \\
3\end{array}$ & $\sum_{m}$ & 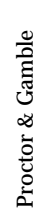 & 3 & 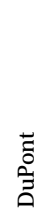 & 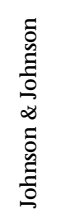 & $\begin{array}{l}\frac{y}{\frac{10}{0}} \\
\stackrel{0}{\underline{y}}\end{array}$ & $\begin{array}{l}\frac{u}{u} \\
\frac{\pi}{\Sigma}\end{array}$ & $\sum_{\underline{M}}$ & 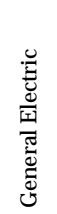 & 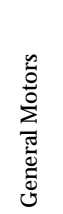 & 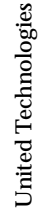 & $\begin{array}{l}\overline{\overline{0}} \\
\text { y } \\
\bar{\alpha}\end{array}$ & 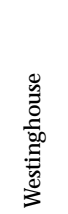 & $\begin{array}{l}\frac{d}{0} \\
\frac{\pi}{0} \\
\frac{3}{4}\end{array}$ \\
\hline
\end{tabular}

\section{Corporate policies and}

investments

$\begin{array}{llllllllllllllllllllllllllllll}\text { Corporate commitment } & 1 & 1 & 1 & 2 & 1 & 1 & 1 & 1 & 2 & 2 & 2 & 1 & 2 & 2 & 2 & 0 & 1 & 2 & 1 & 1 & 2 & 2 & 2 & 1 & 1.4\end{array}$ Environmental auditing Environmental

$\begin{array}{lllllllllllllllllllllllllllllll}\text { management structure } & 1 & 0 & 0 & 0 & 1 & 0 & 0 & 0 & 0 & 0 & 1 & 0 & 0 & 0 & 0 & 0 & 0 & 1 & 0 & 0 & 1 & 0 & 0 & 1 & 0.3\end{array}$ $\begin{array}{llllllllllllllllllllllllllllll}\text { Environmental policy } & 1 & 1 & 0 & 0 & 1 & 1 & 1 & 1 & 1 & 1 & 1 & 0 & 1 & 1 & 1 & 1 & 1 & 1 & 1 & 0 & 1 & 1 & 1 & 1 & 0.8\end{array}$ $\begin{array}{lllllllllllllllllllllllllllllll}\text { Industry involvement } & 1 & 1 & 1 & 0 & 1 & 1 & 1 & 0 & 1 & 0 & 0 & 1 & 1 & 1 & 1 & 1 & 1 & 1 & 1 & 0 & 1 & 0 & 1 & 0 & 0.7\end{array}$ $\begin{array}{llllllllllllllllllllllllllll}\text { Research and development } & 2 & 2 & 2 & 2 & 2 & 2 & 1 & 0 & 2 & 2 & 1 & 2 & 2 & 2 & 2 & 2 & 2 & 2 & 2 & 1 & 2 & 2 & 2 & 1 & 1.8\end{array}$ Support environmental organizations

Total environmental expenditures

Regulatory information

Air emissions

Environmental compliance

Reductions in ODC use

Remediation

Superfund status

Underground storage

$$
\text { tanks }
$$

Wastewater treatment

Pollution prevention

Energy conser vation

Life-cycle analyses

Packaging reductions

Recycling

Reuse of recycled materials

Waste reduction efforts

Employee involvement

Employee environmental

$$
\text { education program }
$$

Employee

recognition/awards $\quad \begin{array}{llllllllllllllllllllllllllllllllll} & 1 & 0 & 0 & 0 & 1 & 0 & 0 & 0 & 0 & 0 & 0 & 1 & 0 & 1 & 1 & 0 & 0 & 0 & 1 & 0 & 0 & 1 & 1 & 0 & 0.3\end{array}$

Community involvement

Community involvement

Community

panels/ information$$
\text { center }
$$

Emergency response teams

Miscellaneous

Awards

management/ ecology
Response card

Pages of text

Figures and tables (N)

Photographs (N)

Guideline useda

\section{Summary}

Corporate policies and investments

Community involvement

Employee involvement

Regulatory information

Pollution prevention

Total points

SIC category

SIC code

SIC code

SIC code

$\begin{array}{llllllllllllllllllllllllllllll}1 & 1 & 1 & 1 & 1 & 0 & 1 & 0 & 0 & 1 & 0 & 1 & 1 & 0 & 0 & 1 & 1 & 1 & 1 & 1 & 1 & 1 & 1 & 0 & 0.7\end{array}$

$\begin{array}{llllllllllllllllllllllllll}1 & 1 & 1 & 1 & 1 & 1 & 0 & 0 & 1 & 1 & 0 & 1 & 0 & 1 & 1 & 0 & 0 & 1 & 0 & 0 & 0 & 0 & 0 & 0 & 0.5\end{array}$

$\begin{array}{llllllllllllllllllllllllllll}2 & 2 & 0 & 1 & 1 & 1 & 1 & 0 & 1 & 2 & 2 & 2 & 1 & 2 & 2 & 1 & 2 & 2 & 2 & 2 & 2 & 2 & 2 & 2 & 1.5\end{array}$

$\begin{array}{llllllllllllllllllllllllllllll}1 & 0 & 0 & 0 & 1 & 1 & 0 & 0 & 1 & 1 & 1 & 1 & 0 & 1 & 1 & 0 & 0 & 1 & 1 & 0 & 1 & 1 & 1 & 0 & 0.6 \\ 2 & 0 & 0 & 0 & 0 & 0 & 1 & 0 & 0 & 0 & 0 & 1 & 0 & 2 & 2 & 1 & 1 & 1 & 2 & 2 & 2 & 2 & 2 & 1 & 0.9\end{array}$

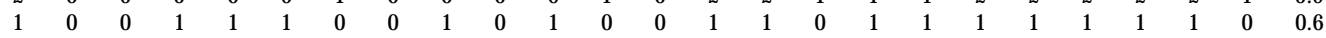

$\begin{array}{llllllllllllllllllllllllllllll}1 & 0 & 1 & 1 & 1 & 1 & 0 & 0 & 1 & 0 & 1 & 0 & 0 & 1 & 1 & 0 & 0 & 1 & 0 & 1 & 1 & 1 & 1 & 0 & 0.6\end{array}$

$\begin{array}{llllllllllllllllllllllllll}0 & 1 & 0 & 1 & 0 & 0 & 0 & 0 & 1 & 0 & 0 & 1 & 0 & 0 & 1 & 1 & 1 & 0 & 0 & 0 & 0 & 0 & 0 & 0 & 0.3 \\ 0 & 2 & 0 & 0 & 1 & 1 & 1 & 0 & 1 & 2 & 2 & 2 & 1 & 1 & 0 & 0 & 2 & 0 & 0 & 0 & 1 & 0 & 0 & 1 & 0.8\end{array}$

SIC code

$$
\begin{aligned}
& \begin{array}{llllllllllllllllllllllllll}
1 & 0 & 0 & 0 & 1 & 0 & 0 & 0 & 1 & 0 & 0 & 0 & 0 & 1 & 1 & 0 & 1 & 1 & 0 & 0 & 1 & 0 & 0 & 0 & 0.3 \\
1 & 1 & 1 & 1 & 1 & 0 & 0 & 0 & 0 & 0 & 0 & 0 & 0 & 0 & 1 & 1 & 1 & 1 & 0 & 0 & 1 & 0 & 1 & 0 & 0.5
\end{array} \\
& \begin{array}{lllllllllllllllllllllllllllll}
0 & 0 & 1 & 0 & 1 & 1 & 1 & 0 & 1 & 1 & 0 & 1 & 0 & 0 & 1 & 0 & 1 & 1 & 1 & 1 & 1 & 0 & 1 & 1 & 0.6
\end{array}
\end{aligned}
$$

aGuideline used: $\mathrm{P}=\mathrm{PERI}, \mathrm{I}=\mathrm{ICC}, \mathrm{C}=$ CERES.

bTotal includes five summary items plus first three miscellaneous items.

'SIC codes: Listing of major codes used. 
initiative through its goals of performance improvement and communication (Elkington and Robins 1994). In addition, adoption by firms of the voluntary standards and guidelines for environmental management systems (ISO 1996), under development since 1991, may enhance the credibility of some information in environmental reports, specifically that addressing environmental audits, environmental labeling, and lifecycle analysis.

\section{Use and Limitations of Guidelines and Principles}

Both PERI and CERES guidelines provide helpful information to firms preparing environmental reports. Each of the seven firms that stated the PERI guidelines were used in the preparation of its reports (Table 3 ) scored above average (average total score of $27.5 \pm 2.6$ of 38 possible). The PERI guidelines give categories of suggested information, but allow considerable flexibility. The single report prepared using the CERES guidelines (by Georgia-Pacific) scored above average (score of 30.0). The CERES guidelines are very specific, and including all requested information resulted in a lengthy report ( 36 pages compared to average of 24). In contrast, the mean score of the four firms using the ICC guidelines was lower $(23.0 \pm 4.8)$.

Selective coverage of topics is a major issue that is only partially addressed by the existing guidelines for environmental reports. A report may not reflect all activities and programs of environmental significance. Conversely, report omissions do not mean that a firm is environmentally irresponsible. In addition, the coverage of a report will be influenced by the intended audience. To simultaneously reach and satisfy the community, environmental groups, regulators, employees, and investors, reports are often broad in scope. Other reports take a selective approach and target only one or two groups.

No guideline makes any attempt to initiate comparative measures, e.g., comparing environmental performance or environmental spending and liabilities to industry averages, those of other firms, or other benchmarks. Guidelines do not specify the use of product life-cycle analyses, the normalization of emissions by production data, or other measures useful for inter-and intrasector analyses. Other potentially useful tools include safety and health assessments and risk-costbenefit studies. While such analyses may be technically challenging and subject to several significant limitations, industry has begun to quantify such information, which is often viewed as essential in determining the competitiveness of firms and in guiding future actions. The exclusion of this information, as well as the selective use or omission of other data, diminishes the value of these reports. Although the guidelines encourage or mandate company-specific information, evaluations and comparisons based on reported information may not be meaningful. Like self-conducted environmental audits, a firm may feel that publication of negative environmental information may induce regulatory or legal reprisals, e.g., a regulatory enforcement investigation. Selective reporting is one of the most significant concerns that limits the use of the existing environmental reports.

\section{Report Content}

While the reports collected from the Fortune 50 firms are diverse, some generalizations can be made. Typically, a report opens with a letter or statement of environmental commitment from the CEO or highest ranking environmental executive, followed by the firm's environmental policy and often the organizational structure of the environmental department. Most reports then present information on various environmental topics, e.g., emissions, recycling programs, hazardous and solid waste stream reductions, environmental audit programs, and research efforts. Many topics are reported using graphs that chart progress from a base year. Environmental spending, fines, and violations are frequently reported. Specific topics tend to vary by industry, e.g., the paper industry focuses on timber management, biochemical oxygen demand of water, and wild life habitat, while the chemical industryemphasizes chemical emissions, emergency response, community relations, and community communications. Major topics presented in the reports are discussed below by category.

Corporate policies and investments. This category is constructed from eight topics that evaluate issues typically managed at the corporate level. These topics are oriented toward the investor, rather than the consumer. Reports can serve as a mechanism for feedback on the firm's environmental record, allowing the firm to apply resources in areas of interest to investors and other stakeholders.

Regulatory information. This category includes information on environmental activities required by law, for example, TRI emission data. Some, but not necessarily all, of this information is public record. Reports provide an opportunity for the firm to argue its side of violations and/ or fines. This information is useful for environmental groups and community members who may pursue action, given repeated violations of laws. The primary beneficiary of this information, however, may be investors, e.g., mutual funds, foundations, pension funds, investors, and others who screen investments. Institutional investors hold $53 \%$ of US equities and focus 
groups of investors have indicated that some information found in environmental reports is of interest, i.e., environmental liabilities and litigation (IRRC 1992). Investment decisions by fund managers and individuals may be affected by the environmental reputation of a firm as represented in an environmental report.

Environmental reports may make a positive impact on regulators and legislators that helps to forestall future regulatory actions and environmental legislation, or they may serve to target other "less responsible" industries. The publication of voluntary reports also may convince legislators that mandated environmental reporting is unnecessary or should not be expanded.

Pollution prevention. This category includes information not required by law that shows the environmental "friendliness" of the firm and frequently its fiscal responsibility through cost savings. This information is useful to investors and environmental groups. It also may be geared towards legislators as most reports emphasize the proactive stance of their pollution prevention activities.

Employee involvement. This category has two items that focus on training and recognition for environmental excellence. Reports devoted to employee concerns help to encourage and reinforce the importance of environmental protection. 3M's report, for example, subtitled "Recognizing Employee Contributions," is dedicated to $3 \mathrm{M}$ employees and opens with a letter addressed to them. Reports may present understandable and pertinent environmental information to company managers who may not be well versed in environmental issues. Educating company personnel may improve decisions and environmental management.

Community involvement. This category indicates the involvement with surrounding communities, and the inclusion of many items in this category indicates a report geared to the community. Good community relations and a public image can benefit sales and attract community members as both employees and customers. Firms may consider environmental reports a worth while and appropriate medium for this effort.

$M$ iscellaneous. This category includes two environmental topics: awards and wildlife management/ ecological information. It also includes general information, e.g., the guidelines, if any, followed in report preparation and numbers of pages, tables, and graphics in the report.

\section{Analysis by Industry Sector}

Of the Fortune 50 companies, 24 (48\%) published environmental reports in 1994 (Table 1). This number is expected to increase as Boeing is expected to publish itsfirst environmental report in 1995, and other firms in the Fortune 50 (Chrysler, Motorola, Digital Equipment) are considering doing so. (Chevron published a report in 1990, but has not published subsequently.) Table 3 lists reporting percentages and average scores by firm. This information is summarized by SIC category in Table 4. DuPont, Kodak, and General Motors produced the highest scoring reports. Both DuPont and Kodak are chemical companies and members of Responsible Care. The chemical and allied products category had a high reporting percentage ( $89 \%$ ) and the highest average score among SIC categories (25.4).

The following gives highlights of reports by SIC category. Where possible, the intended audience is identified.

Lumber and wood products $(S I C=24)$ and paper and allied products $(S I C=26)$. These two categories had a $100 \%$ reporting rate and high total scores. The lumber and wood products average total score (25.3) was second only to that of the chemical industry (25.4), and scores in corporate policies and investments, employee education and recognition, regulatory information, and pollution prevention were significantly above average. Vignettes and photographs were featured, and reports were less technically written than most others. Paper and allied products reports scored well in employee education and recognition and pollution prevention. Reports in both categories were oriented towards employees, surrounding communities, and environmental groups (but not investors), and employee education was stressed.

Reports of firms associated with timber and paper (Weyerhaeuser, Georgia-Pacific, International Paper) contained considerable information on ecology, habitat protection, conservation and water quality issues, e.g., biochemical oxygen demand, effluent treatment, total suspended solids, timber management, dioxin emissions, and land stewardship activities. These topics were not found in other reports. TRI and other emissions data were noted but not emphasized. Several topics, e.g., emergency response and reductions in ozonedepleting chemical usage, may have little applicability to this industry. $\mathrm{H}$ ad these issues been reflected in the total score, these reports would have scored among the highest of those examined. The lumber industry, a frequent and well-publicized target of environmental groups, is often at the forefront of environmental debates, and their reports may respond to this attention. The emphasis on environmental education may reflect the involvement of many employees with natural resource issues.

The 3M and Procter \& Gamble reports provided limited information on paper and related products and operations, but instead focused on their chemical and 
Table 4. Broad category comparison showing mean scores by SIC code ${ }^{a}$

\begin{tabular}{|c|c|c|c|c|c|c|c|c|}
\hline Category & $\begin{array}{l}\text { Number } \\
\text { of firms }\end{array}$ & $\begin{array}{l}\text { Reporting } \\
\text { percentage }\end{array}$ & $\begin{array}{c}\text { Corporate } \\
\text { policies and } \\
\text { investment }\end{array}$ & $\begin{array}{l}\text { Community } \\
\text { involvement }\end{array}$ & $\begin{array}{l}\text { Employee } \\
\text { education and } \\
\text { recognition }\end{array}$ & $\begin{array}{l}\text { Regulatory } \\
\text { information }\end{array}$ & $\begin{array}{l}\text { Pollution } \\
\text { prevention }\end{array}$ & $\begin{array}{l}\text { Total } \\
\text { score }\end{array}$ \\
\hline $\begin{array}{l}\text { Lumber and wood } \\
\text { products }\end{array}$ & 3 & 100 & $7.7^{*}$ & 1.0 & $0.7^{*}$ & $6.0 *$ & $7.7^{*}$ & 25.3 \\
\hline $\begin{array}{l}\text { Paper and allied } \\
\text { products }\end{array}$ & 4 & 100 & 7.3 & $0.8^{*}$ & $0.8^{*}$ & 5.0 & $8.0^{*}$ & 24.0 \\
\hline $\begin{array}{l}\text { Food and kindred } \\
\text { products }\end{array}$ & 9 & 33 & $5.0^{*}$ & $0.7^{*}$ & $0.3^{*}$ & $2.7^{*}$ & 7.0 & 17.0 \\
\hline $\begin{array}{l}\text { Transportation } \\
\text { equipment }\end{array}$ & 9 & 33 & 6.7 & 1.3 & $0.3^{*}$ & $7.0^{*}$ & $5.3^{*}$ & 22.0 \\
\hline $\begin{array}{l}\text { Chemicals and } \\
\text { allied products }\end{array}$ & 9 & 89 & $8.0 *$ & $1.8^{*}$ & 0.5 & 5.8 & $7.4^{*}$ & 25.4 \\
\hline $\begin{array}{l}\text { Measurement, } \\
\text { analysis, control } \\
\text { equipment }\end{array}$ & 5 & 80 & 7.0 & 1.5 & 0.5 & 5.8 & 6.3 & 22.8 \\
\hline $\begin{array}{l}\text { Wholesale trade } \\
\text { Oil and gas }\end{array}$ & 4 & 75 & 7.0 & 1.0 & $0.3^{*}$ & $4.0^{*}$ & 7.0 & 20.3 \\
\hline extraction & 8 & 50 & 7.5 & 1.3 & $0.3^{*}$ & $4.3^{*}$ & 6.3 & 21.0 \\
\hline $\begin{array}{l}\text { Petroleum refining } \\
\text { Pipelines, }\end{array}$ & 7 & 43 & $8.7^{*}$ & $2.0^{*}$ & $0.7^{*}$ & 5.3 & $5.3^{*}$ & 23.7 \\
\hline $\begin{array}{l}\text { excluding } \\
\text { natural gas } \\
\text { Industrial }\end{array}$ & 10 & 50 & $8.0^{*}$ & 1.6 & 0.4 & $4.4^{*}$ & $5.8^{*}$ & 21.8 \\
\hline machinery/ computer & 3 & 33 & 7.0 & $0.0^{*}$ & $1.0^{*}$ & $6.0^{*}$ & $9.0^{*}$ & 25.0 \\
\hline $\begin{array}{l}\text { Average } \\
\text { Highest possible }\end{array}$ & 6.5 & 48 & 7.2 & 1.3 & 0.5 & 5.3 & 6.8 & 22.8 \\
\hline score & NA & 100 & 11.0 & 2.0 & 2.0 & 10.0 & 9.0 & 38.0 \\
\hline
\end{tabular}

aAsterisk indicates statistical significant difference from mean ( $\alpha=0.05$ level using a two-tailed $t$ test). Although not shown, the miscellaneous category is included in the total score. Averages are taken across the 24 available reports ( they are not column averages).

packaging operations. Neither firm is strongly associated with the paper industry, and many concerns of the paper industry, e.g., recycled content, dioxin, chlorine and forestry management, were largely omitted. (Firms in the lumber and wood products classification generally provided good coverage of these concerns, e.g., dioxin received about one paragraph in each report, and Weyerhaeuser listed a document on dioxin that can be ordered.)

Food and kindred products $(\mathrm{SIC}=20)$. Firms in this category have a low reporting rate (33\%). These firms may not be motivated to produce reports given the scant public attention the food industry's environmental impacts receive. With the exception of Bristol-Myers Squibb's (BMS) report, reports scored below average (average score of 17). BMS is perceived as a pharmaceutical rather than a food manufacturer and its report responds to pharmaceutical and chemical industry issues. Thus, the BMS report is evaluated under the chemicals and allied products. For Phillip Morris and Sara Lee, the remaining food industry firms publishing reports, total scores were the lowest among the SIC categories evaluated, and scores were significantly below average in every category except pollution preven- tion. Reports were short, consisting mainly of photographs, sketches and generalizations regarding recycling or pollution prevention programs. Corporate policies were omitted. Relatively few environmental regulations may affect these firms, and firms may not be inclined to report regulatory information.

The intended audiences for the Sara Lee and Philip Morris reports are unclear. Inadequate information is provided for investors or environmental groups. Employee efforts, community programs, and environmental efforts at individual plants received little attention. Because both reports emphasized environmental management, investors may be the intended audience. However, additional information seems necessary to persuade investors, e.g., statistics on waste reduction, pollution prevention, and other activities. Photographs and charts would improve the readability of the reports.

Transportation equipment ( $\mathrm{SIC}=37$ ). These category had a low reporting percentage (30\%), although Chrysler and Boeing mentioned possible and pending publication, respectively. Only about half the firms in this category are directly associated with transportation equipment and, of these, only General Motors (GM) published a report. Available reports scored above 
average in regulatory information, and below average in pollution prevention and employee education and recognition. These scores may reflect public attention to more obvious environmental targets, e.g., oil and chemical companies, rather than the transportation industry's indirect and rarely life-threatening impacts, e.g., $\mathrm{CO}_{2}$ emissions and smog. The GM and United Technologies reports were comprehensive and readable. While shorter and less informative, the General Electric report was embellished with graphs. These three reports had no major omissions and focused on chemical emissions and product design. These reports described environmental impacts during manufacturing, like many other reports outside of thiscategory, but these also included impacts during product use. Product design and use are especially important in transportation since many impacts are associated with energy use and combustion.

While multiple audiences were targeted, investors seem the principal audience of the transportation reports. For this audience, regulatory information such as large Superfund expenses and environmental fines is of primary importance, while voluntary programs in pollution prevention, employee education and recognition, etc., may be only a secondar y concern.

Chemicals and allied products (SIC $=28)$. This category had a high ( $89 \%$ ) response rate and most reports were outstanding (average total score of 25.4). Sufficient information was presented to satisfy investors, environmental groups, employees, regulatory agencies, and customers. The reports tended to be dry, with few photographs or human interest articles, and were oriented to technical audiences. Photographs and human interest vignettes would enhance these reports and increase their appeal to employees and customers.

The Proctor \& Gamble report, one of the two weaker reports, contained few data on recycling and pollution prevention and omitted Superfund status, environmental auditing, and environmental compliance. The report was the least polished of those in this category. The second, by Johnson \& Johnson, omitted information on Superfund and environmental compliance. However, this report was professionally done, globally oriented, and appealing to employees and customers. Environmental groups, regulatory agencies, and investorswould probably require more data, however.

Chemical firms are among the largest polluters in the United States when ranked by TRI emissions, and they are often viewed as undesirable community neighbors. Many chemicals produced have unfamiliar names, few are purchased directly by the public, and the press and environmentalists tend to portray this industry negatively. This reputation may help to explain the high reporting percentage and the generally high quality of these reports.

Measuring, analyzing, and controlling equipment (SIC = 38). This category contains a diverse group of firms, e.g., Bristol-Myers Squibb is often associated with the chemical and pharmaceutical industries, while Xerox and Eastman Kodak produce consumer goods and other products. The breadth of this category al lows few strong conclusions. The total reporting rate $(80 \%)$ was above average, possibly due to these firms' desire to maintain a good reputation among customers and others. (A report was received from Xerox in mid-1995, too late for inclusion in this paper.)

Wholesale trade $(\mathrm{SIC}=51)$. This category had a high reporting rate $(75 \%)$ and again includes a broad spectrum of firms, e.g., two associated with tobacco and two with oil and gas. These firms are widely recognized, and the high reporting percentage may reflect the importance of a good corporate image.

$\mathrm{O} \mathrm{il}$ and gas extraction $(\mathrm{SIC}=13$ ) and petroleum refining (SIC = 29). Reporting rates for extraction and refining industries (50\% and $43 \%$, respectively) and average total scores (21.0 and 23.7) were comparable to the Fortune 50 average. For extraction firms, scores are significantly below average in employee education, employee recognition, and regulatory information. Refiners scored well in corporate policies and investments, community involvement and employee education and recognition, but poorly in pollution prevention. These scores may reflect the public's attention to catastrophic accidents rather than to more routine and seemingly benign violations of environmental laws. The high scores in policies and investment may reflect concerns with past or possible oil spills, e.g., the Exxon Valdes incident, which raised questions regarding employee supervision, the use of single-hull tanker ships, etc. Many reports emphasized proactive efforts, e.g., additions of double-hulled tankers to their fleet and training programs for ship captains.

Pipelines (except natural gas) (SIC $=46$ ). This classification includes firms typically regarded as oil and gas companies. The reporting rate (averaging 50\%) seems associated with company size, i.e., the three largest pipeline firms published environmental reports, and the two smallest did not. The average report score (21.8) was just below average. Reports scored significantly above average in corporate policies and investments, but significantly below average in regulatory information and pollution prevention. Most reports were thorough and readable. Topics of interest to both the public and investors were covered, e.g., incident prevention, chemical emissions, emergency response, wildlife protection, and incident prevention programs. 
Most mentioned TRI emissions and emergency response activities. Two reports are addressed to "shareholder," the apparent primary audience for all reports in this category. The reports also addressed many concerns of surrounding communities, investors, employees, and environmental groups. While the Mobil report was an awkward size ( $3.5 \times 8$ in.) and without photographs or charts, it contained most of the relevant information.

Industrial and commercial machinery/computers $(\mathrm{SIC}=35)$. This category had the lowest reporting rate $(25 \%)$, with only IBM publishing a report. Given this category's diversity and small number of firms, e.g., Caterpillar, Digital Equipment and IBM, no strong conclusions are possible.

\section{Motivation and Intended Audience}

Most environmental reports emphasize industryspecific issues. Industries with a poor public image tend to respond the most aggressively. Firms may feel that environmental reports help to alter public opinion and enhance a firm's image. Proactive community programs, emission reductions, and information on other environmental efforts presented in the report may assuage neighbors, individuals, environmental groups, and other organizations. While firms publishing reports have various concerns and thus address different issues, enhancement of a firm's image appears the most obvious and common reason for publishing, especially for industries that receive considerable negative press. Business benefit may be the second major motivation. Shareholders and investors frequently have concerns about a firm's environmental impact and how resources are used to manage environmental issues. Some reports appear to target environmental groups and surrounding communities, audiences that may have preconceived notions regarding a firm's environmental impact. In this case, reports focus on these concerns, and other topics may not be addressed.

\section{Evaluating Environmental Reporting}

Environmental reports of the Fortune 50, the largest US firms, represent an important communication effort that supplements information issued for regulatory, financial, and press purposes. Presumably, the largest firms have the resources to develop and distribute these reports. Several reports were well done and scored high in most or all categories, although none could be considered a model report for reasons discussed later (see Recommendations below).

Significant differences were seen between industry sectors using both qualitative descriptions and quantita- tive rankings, which were generallycorroborative. Quantitative rankings may have several shortcomings. First, rankings based on total scores assume that additional information, including both breadth and depth, is better. The importance of information may vary by industry and may be difficult to evaluate. A firm may not present information on some topics because it does not appear relevant to the target audience or to the firm's operations, e.g., emergency response issues may not critical to the food industry. Most topics, however, were broad and seem relevant to most firms. Reports could simply state that no significant actions occur on certain topics. Second, each topic was assumed to contribute equally to the total score. For example, the lack of emission data and a reader response card were scored equally. $\mathrm{H}$ owever, individual topic scores are presented, from which other rankings might be developed. Third, every topic mentioned in the reports was not included. As mentioned, this lowered scores for firms in lumber and wood products.

The cross-sectional comparison involves several difficulties. First, SIC codes may not reflect all of a firm's activities or its perception by the public. For example, while classified in paper and allied products, 3M is often viewed as a chemical manufacturer. Accordingly, 3M's report gives cursory treatment to paper industry issues. As a second example, Bristol-Myers Squibb, a top food products company, is perceived primarily as a pharmaceutical company. Since environmental reports are primarily written to address public concerns, comparisons might be based on the public perception of the firm or possibly the intended audience, if stated. Second, the small sample size and large number of SIC categories hinders statistical conclusions and makes it difficult to generalize results. A larger sample, e.g., the Fortune 500, could address this shortcoming. Third, environmental reporting is dynamic and responds to rapidly changing factors. The evolution and prediction of future reporting trends is beyond the present scope.

\section{Recommendations}

Based on the guidelines and reports examined, several recommendations are made regarding the development and use of environmental reports.

- Environmental reports provide opportunities for a firm to reach a variety of audiences and present largely nontechnical information that describes the scope and commitment of the firm's environmental efforts. Consequently, reports should place greater 
emphasis on policy, education, and progress in meeting environmental goals.

- Before publishing a report, firms should identify the intended audience(s) and design the report for them. The audience should be identified early in the report. In most cases, technical audiences will not be satisfied with the information presented for the public; thus reports should specify methods to obtain more comprehensive data. The use of an Internet bulletin board or Worldwide Web site is suggested as a way to keep information current.

- Draft reports should be evaluated using small surveys, focus groups, or other means. If the report is not communicating the desired message, it should be redesigned. Although apparently neglected by many firms, an evaluation of the communications effort is vital. Evaluation was not mentioned in any published articles reviewed for this document, and conversations with company representatives indicate that eval uations are not usually performed.

- Environmental reports cannot be used to judge or evaluate a firm's environmental commitments, liabilities, and performance. While reports compiled using the PERI and particularly the CERES guidelines should encompass the appropriate topics, there is no quality-control system or other means to assure that reporting is comprehensive. Rather, environmental reports must be viewed with the perspective that image building is the firm's major motivation for publishing.

- A need exists for guidelines that specify a means to perform and report a comprehensive evaluation of a firm's environmental record and the environmental impacts of its products and services. Rather than addressing an audience of the general public, such reports would be fairly technical and probably of greatest benefit to industry itself, e.g., providing "benchmarks" of environmental impacts and performance for specific products which firms would strive to better. Guidelines for such reports should utilize life-cycle assessments and encompass a means to verify the accuracy and comprehensiveness of information (possibly by an independent certification body). Similar to or possibly part of the ISO (1996) 14000 Environmental Management System standards and guidelines, environmental report guidelines might be developed by industry, environmental, or third-party organizations.

\section{Acknowledgments}

The authors acknowledge the helpful discussions provided by representatives of the Fortune 50 firms. Steve Willis of Whirlpool Corporation provided invaluable help and advice. Partial support was provided by the $\mathrm{H}$ azardous Substances Academic Training Program, a component of the Educational Resource Center at the University of Michigan supported by the National Institute of O ccupational Safety and $\mathrm{H}$ ealth.

\section{Literature Cited}

Cahill, L. B., and R. W. Kane. 1994. Corporate environmental performance expectations in the 1990s: More than just compliance. Total Quality Environmental M anagement 3:409420.

CERES (Coalition for Environmentally Responsible Economies). 1992. CERES Report: 1991 environmental performance report. Boston, Massachusettes.

CEFIC (European Chemical Industry Council). 1993. CEFIC guidelines on environmental reporting for the European chemical industry (draft). Brussels, Belgium.

Dun and Bradstreet. 1994. Dun's business rankings. Bethlehem, Pennsylvania.

Elkington, J., and N. Robins. 1994. The corporate environment report. UNEP Industry and Environment Programme Activity Centre, New York.

Forrest, C. J., and R. A. Axelrod. 1995. Businesses find value in environmental report cards. Environmental Solutions 8:34-35.

ICC (International Chamber of Commerce). 1991. The business charter for sustainable devel opment. Paris, France.

IRRC (Investor Responsibility Research Center). 1992. Institutional investor needs for corporate environmental information. Washington, DC.

ISO (International Standards Organization). 1996. Standard 14000-environmental management standards. Environmental management systems-specification with guidance for use. ISO 14004-Environmental management systemsgeneral guidelines on principles, systems and supporting techniques. Geneva, Switzerland.

Knapp, B. D., T. Wesolofski, and T. J. Scott, Companies respond to increased scrutiny with broader disclosure of environmental liabilities. Engineering N ews Record 232:E69E70.

KPMG. 1993. International survey of environmental reporting. Klynveld, Peat, Marwick, Goerdeler, Environmental Practice Group, Dallas, Texas.

Naimon, J. 1994. Lifting the veil. Tomorrow 1:58-66.

PERI (Public Environmental Reporting Initiative). 1993. PERI guidelines. Stamford, Connecticut.

Sandborg, V. 1993. Producing an environmental report. Journal of Environmental Regulation 3:57-68. 